\title{
Comparison of maternal serum CA-125 and ultrasonography findings as a prognostic marker in threatened abortion
}

\author{
Kamlesh Yadav, Pragya Ojha*, Anant Chopra
}

\begin{abstract}
Department of Obstetrics and Gynaecology, Sardar Patel Medical College and Associated Group of Hospitals, Bikaner, Rajasthan, India
\end{abstract}

Received: 22 March 2021

Revised: 23 April 2021

Accepted: 27 April 2021

\author{
*Correspondence: \\ Dr. Pragya Ojha, \\ E-mail: pragyash125@gmail.com
}

Copyright: ( ) the author(s), publisher and licensee Medip Academy. This is an open-access article distributed under the terms of the Creative Commons Attribution Non-Commercial License, which permits unrestricted non-commercial use, distribution, and reproduction in any medium, provided the original work is properly cited.

\begin{abstract}
Background: WHO defines abortion as pregnancy termination before 20 week gestation or with fetus born weighing $<500$ gms. Early pregnancy markers in patients with threatened abortion including biochemical marker like raised maternal serum CA-125 (cancer antigen-125, carcinoma antigen 125 or carbohydrate antigen 125) and USG parameters that is, fetal crown-rump length (CRL), the presence/absence of sub-chorionic hematoma and fetal heart rate (FHR) are good predictors of outcome.

Methods: The study was conducted in the department of obstetrics and gynaecology, S.P. medical college and associated group of hospital, Bikaner, Rajasthan. This was a hospital based prospective comparative study. The study group comprise of pregnant females attending obstetrics and gynaecology OPD. A total of 200 pregnant women were examined in this study. We divided these patients into 2 groups, group A and group B. Group A consists of 100 pregnant females with threatened abortion and group B with 100 normal pregnant female.

Results: Maternal serum CA-125 at cut off level $61.64 \mathrm{U} / \mathrm{ml}$ is $84.21 \%$ sensitive, $96.77 \%$ specific in predicting abortion with $94.12 \%$ positive predictive value and $90.91 \%$ negative predictive value while FHR at $115 \mathrm{bpm}$ is $76.32 \%$ sensitive, $90.32 \%$ specific in predicting abortion with $82.86 \%$ PPV and $86.15 \%$ negative predictive value.

Conclusions: Single raised value of maternal serum CA-125 has best predictive value followed by USG parameters (FHR, sub-chorionic hematoma and CRL) in threatened abortion which results in loss of pregnancy.
\end{abstract}

Keywords: Pregnancy, Abortion, Threatened, CA-125, USG

\section{INTRODUCTION}

WHO defines abortion as pregnancy termination before 20 weeks gestation or with fetus born weighing $<500$ gms. ${ }^{1}$ More than 80 percent of abortions occur in the first trimester of pregnancy and half of these result from chromosomal anomalies. After the first trimester the abortion rate and chromosomal anomalies both decreases. ${ }^{2}$ Abortion may be spontaneous or induced. Threatened abortion is a type of spontaneous abortion.
According to WHO threatened abortion is, pregnancy related bloody vaginal discharge or frank bleeding during its first half of pregnancy without cervical dilatation. ${ }^{3}$ It is usually happen in around one-fifth of pregnancy. ${ }^{4}$

Threatened abortion progress to pregnancy loss in about 50 percent cases. Additionally, first trimester bleeding assumes a role in the occurrence of late pregnancy complication. ${ }^{5-8}$ Hence by preventing and managing threatened abortion complications can be avoided. 
Numerous sonographic criteria and biochemical markers have been studied to predict the outcome of threatened abortion. ${ }^{9}$

Various sonographic signs have been described to predict pregnancy outcome. Gestational sac not corresponding to gestational age or irregularly shaped gestational sac, a low implantation site, a large or irregular yolk sac, a weak decidual reaction, and slow embryonic heart rate are used as predictors of pregnancy outcome. ${ }^{10}$

Early pregnancy markers in patients with threatened abortion including the size of gestational sac, size and shape of yolk sac, fetal CRL, the presence/absence of sub-chorionic hematoma and FHR are good predictors of outcome.

CA-125 is cell surface high molecular weight glycoprotein present in tissue derived from embryonic coelomic. ${ }^{11}$ During pregnancy, disruption of the epithelial basement membrane of the fetus or disruption of the decidua could theoretically lead to rise in maternal CA125 level, thus can be used as a predictor of subsequent spontaneous abortion.

\section{METHODS}

\section{Study population}

The study was conducted in the department of obstetrics and gynaecology, S.P. medical college and associated group of hospital, Bikaner, Rajasthan from 1 September 2019 to 31 August 2020. This is a hospital based prospective comparative study. The study group comprise of pregnant females attending obstetrics and gynaecology OPD. A total of 200 pregnant women were examined in this study. We divided these patients into 2 groups, group A and group B. Group A consists of 100 pregnant female with threatened abortion and group B with 100 normal pregnant female.

\section{Inclusion criteria}

Patient who presented with complain of vaginal bleeding, closed and uneffaced cervix and/or abdominal pain at 612 weeks of gestational age were included in the study. The pregnancy should be confirmed by a visible gestational sac of a live embryo, verified by cardiac activity on a real time ultrasound and gestational age was calculated by their last menstrual period, in both groups. Study population included women of 18 to 40 years age group.

\section{Exclusion criteria}

Other abortions (incomplete or missed abortion), molar pregnancy, ectopic pregnancy, women not willing to participate in the study were excluded.

\section{Data collection}

After careful and thorough history, physical examination, sonography done to confirm gestational age, fetal viability, intrauterine single gestation, after full filling the inclusion criteria and after taking informed consent, the participants were allocated into two groups.

\section{Data analysis}

To collect required information from eligible patients a pre-structured pre-tested performa was used. For data analysis microsoft excel and statistical software SPSS will be used and data were analysed with the help of frequencies, figures, proportions, measures of central tendency, appropriate statistical test.

\section{RESULTS}

Our study population is classified in 2 groups, group A as case and group B as control. Out of 100 patients of group A $62 \%$ patients continued pregnancy and $38 \%$ patients were aborted. For group B $82 \%$ patients continued pregnancy and $18 \%$ were aborted.

In our study, majority $85 \%$ in group A and $96 \%$ patients in group B had no subchorionic haematoma. $15 \%$ in group A and 4\% in group B had subchorionic haematoma. The $\mathrm{p}$ value is 0.008 , the result was significant.

In Table 3 mean FHR and CA-125 for aborted patients is 108.89 per minute and $100.24 \mathrm{U} / \mathrm{ml}$ respectively. For continued patients mean FHR is 128.32 per minute and CA-125 is $32.64 \mathrm{U} / \mathrm{ml}$. FHR, CA-125 showing significant difference in group $\mathrm{A}$ as $\mathrm{p}$ value for these parameter is $<0.0001$. All other demographic and laboratory parameters are non-significant.

Table 1: Distribution of patients in both groups.

\begin{tabular}{|lllll|}
\hline Pregnancy & Group A & & Group B & \\
\hline Continued & Number of patients & Percentage (\%) & Number of patients & Percentage (\%) \\
\hline Aborted & 62 & 62 & 82 & 82 \\
\hline Total & 38 & 38 & 18 & 18 \\
\hline
\end{tabular}


Table 2: Distribution of patients according to subchorionic haematoma.

\begin{tabular}{|llll|ll|}
\hline \multirow{2}{*}{ Subchorionic haematoma } & Group A & & Group B & & \\
& Number of patients & Percentage (\%) & Number of patients & Percentage (\%) & P value \\
\hline Absent & 85 & 85 & 96 & 96 & 0.008 \\
\hline Present & 15 & 15 & 4 & 4 & 0.008 \\
\hline Total & 100 & 100 & 100 & 100 & \\
\hline
\end{tabular}

Table 3: Distribution of patients according to various parameters in group A.

\begin{tabular}{|llllll|}
\hline \multirow{2}{*}{ Parameters } & $\begin{array}{l}\text { Group A } \\
\text { Aborted }\end{array}$ & & Continued & P value \\
& Mean & SD & Mean & SD & \\
\hline Age (in years) & 25.1 & 2.69 & 24.85 & 3.78 & 0.59 \\
\hline Gestational age (in weeks) & 9.05 & 1.74 & 8.66 & 1.74 & 0.11 \\
\hline HB $($ gm/dl) & 9.83 & 1.6 & 10.17 & 1.53 & 0.12 \\
\hline RBS & 118.73 & 14.03 & 119.16 & 12.29 & 0.81 \\
\hline CA-125 (u per ml) & 100.24 & 45.24 & 32.64 & 41.6 & $<0.0001$ \\
\hline CRL (mm) & 19.31 & 13.22 & 22.17 & 15.49 & 0.16 \\
\hline FHR (per minute) & 108.89 & 14.46 & 128.32 & 13.51 & $<0.0001$ \\
\hline
\end{tabular}

Table 4: Distribution of patients according to various parameters in group $\mathbf{B}$.

\begin{tabular}{|c|c|c|c|c|c|}
\hline \multirow{3}{*}{ Parameters } & \multicolumn{4}{|c|}{ Group B } & \multirow{3}{*}{$P$ value } \\
\hline & \multicolumn{2}{|c|}{ Aborted } & \multicolumn{2}{|c|}{ Continued } & \\
\hline & Mean & SD & Mean & SD & \\
\hline Age (in years) & 24.88 & 1.96 & 24.56 & 3.51 & 0.42 \\
\hline Gestational age (in weeks) & 8.88 & 1.64 & 8.54 & 1.81 & 0.16 \\
\hline HB $(\mathrm{gm} / \mathrm{dl})$ & 9.6 & 1.25 & 9.84 & 1.22 & 0.17 \\
\hline RBS & 116.88 & 15.06 & 117.95 & 14.11 & 0.6 \\
\hline CA-125 (u per ml) & 32.45 & 15.94 & 16.39 & 9.5 & $<0.0001$ \\
\hline CRL (mm) & 16.44 & 11.37 & 23 & 15.1 & 0.0006 \\
\hline FHR (per minute) & 105.55 & 5.11 & 127.12 & 14.79 & $<0.0001$ \\
\hline
\end{tabular}

Table 5: ROC analysis for CA-125, FHR and CRL for predicting abortion.

\begin{tabular}{|lllll|}
\hline Parameters & AUC & P value & CI 95\% & Cutoff \\
\hline CA-125 & 0.966 & $<0.0001$ & $0.922-1.011$ & 61.64 \\
\hline FHR & 0.846 & $<0.001$ & $0.755-0.937$ & 115 \\
\hline CRL & 0.606 & 0.076 & $0.485-0.727$ & 11 \\
\hline
\end{tabular}

Table 6: Sensitivity, specificity, PPV, NPV of CA-125 for abortion.

\begin{tabular}{|lll|}
\hline & Aborted & Continued \\
\hline CA-125 (>61.64) & 32 & 2 \\
\hline CA-125 $(\leq \mathbf{6 1 . 6 4 )}$ & 6 & 60 \\
\hline Sensitivity $(\boldsymbol{\%})$ & 84.21 & \\
\hline Specificity $(\boldsymbol{\%})$ & 96.77 & \\
\hline PPV $(\boldsymbol{\%})$ & 94.12 & \\
\hline NPV $(\boldsymbol{\%})$ & 90.91 & \\
\hline
\end{tabular}

Table 4 shows mean CRL for aborted patients is 16.44 $\mathrm{mm}$ and for continued is $23 \mathrm{~mm}$. Mean FHR and CA-125 VALUE for aborted patients is 105.55 per minute and 32.45 U/ml. For continued patients mean FHR is 127.12 per minute and CA-125 is $16.39 \mathrm{U} / \mathrm{ml}$. The $\mathrm{p}$ value for CRL is 0.0006 , for FHR is $<0.0001$ and for CA-125 is $<0.0001$. The result is significant as $p$ value is $<0.05$. All 
other demographic and laboratory parameters are nonsignificant.

ROC curves of CA-125, FHR and CRL in predicting abortion were plotted. The AUC for CA-125, FHR and CRL was 0.966 (95\% CI 0.922-1.011), 0.846 (95\% CI 0.755-0.937) and $0.606 \quad(95 \% \quad$ CI $\quad 0.755-0.937)$, respectively are shown in Table 5 . ROC curve gives cut off level of CA-125 $61.64 \mathrm{U} / \mathrm{ml}$ and FHR $115 \mathrm{bpm}$ and $\mathrm{CRL}$ at $11 \mathrm{~mm}$ in predicting the risk of abortion.
CA-125 is $84.21 \%$ sensitive, $96.77 \%$ specific in predicting abortion with $94.12 \%$ positive predictive value and $90.91 \%$ negative predictive value.

In this study we found that FHR is $76.32 \%$ sensitive, $90.32 \%$ specific in predicting abortion with $82.86 \%$ positive predictive value and $86.15 \%$ negative predictive value.

CRL is $50 \%$ sensitive, $69.35 \%$ specific in predicting abortion with $50 \%$ positive predictive value and $69.35 \%$ negative predictive value.
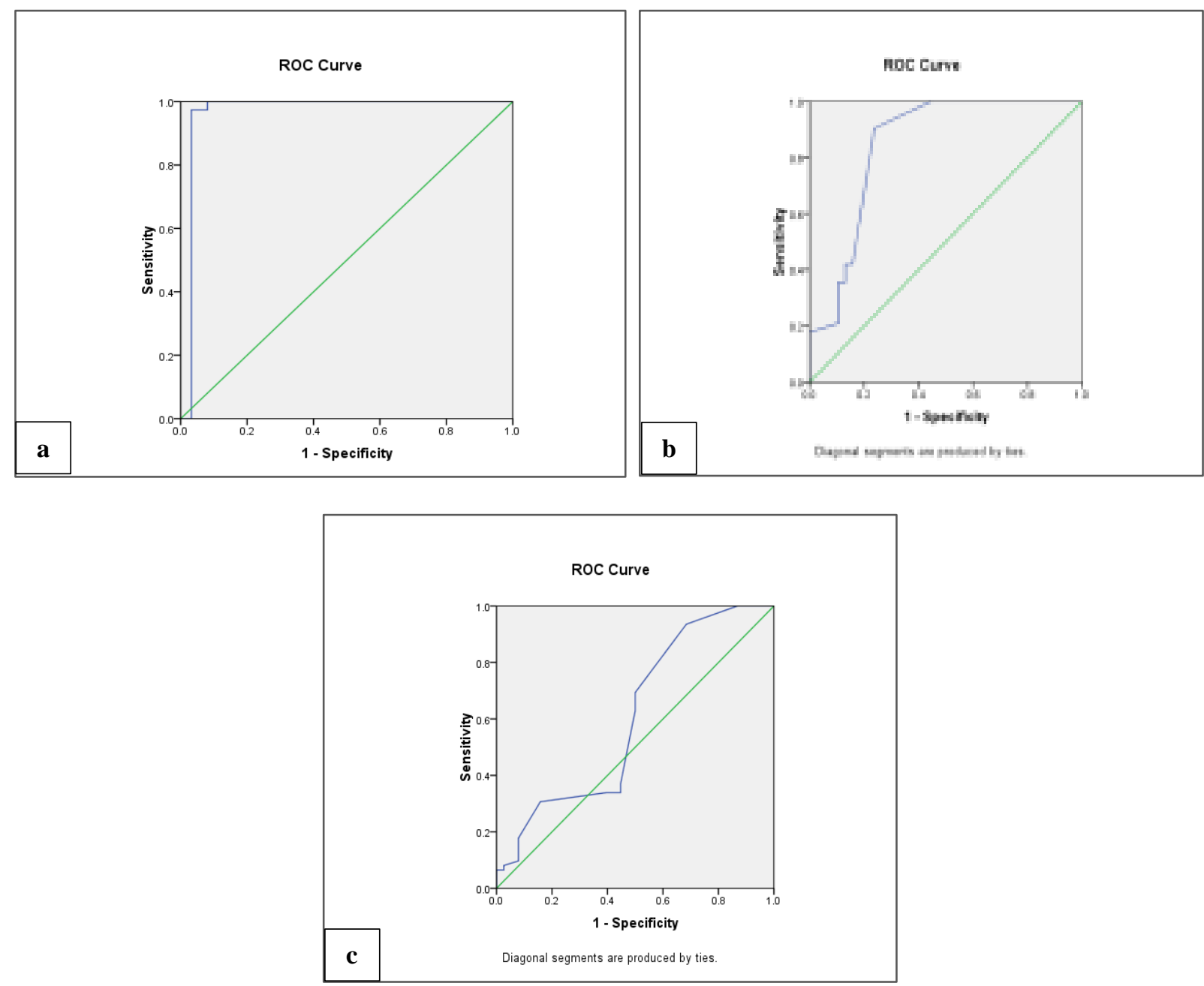

Figure 1: ROC analysis for predicting abortion; (a) CA-125; (b) FHR; (c) CRL.

Table 7: Sensitivity, specificity, PPV, NPV of FHR for abortion.

\begin{tabular}{|lll|}
\hline & Aborted & Continued \\
\hline FHR $(<\mathbf{1 1 5})$ & 29 & 6 \\
\hline FHR $(\geq \mathbf{1 1 5})$ & 9 & 56 \\
\hline Sensitivity (\%) & 76.32 & \\
\hline Specificity (\%) & 90.32 & \\
\hline PPV (\%) & 82.86 & \\
\hline NPV (\%) & 86.15 & \\
\hline Accuracy $(\%)$ & 85 & \\
\hline
\end{tabular}


Table 8: Sensitivity, specificity, PPV, NPV of CRL for abortion.

\begin{tabular}{|lll|}
\hline & Aborted & Continued \\
\hline CRL $(<\mathbf{1 1 )}$ & 19 & 19 \\
\hline CRL $(\mathbf{1 1 )}$ & 19 & 43 \\
\hline Sensitivity (\%) & 50 & \\
\hline Specificity (\%) & 69.35 & \\
\hline PPV (\%) & 50 & \\
\hline NPV (\%) & 69.35 & \\
\hline Accuracy $(\%)$ & 62 & \\
\hline
\end{tabular}

\section{DISCUSSION}

The first trimester vaginal bleeding is common obstetrical complication, occurring in $25 \%$ of all pregnancy. Threatened miscarriage defined as vaginal bleeding before 20 weeks in closed cervical os. According to our study mean age of group A was $24.95 \pm 3.04$ years and in group B was $24.6 \pm 23.28$ years. P value was 0.48 . Most of the patients $66 \%$ and $68 \%$ were illiterate in group A and group B, respectively. Majority, $65 \%$ and $70 \%$ patients were from rural area in group A and group B respectively. $73 \%$ and $74 \%$ patients of group A and group $\mathrm{B}$ respectively were lower class category. In our study $39 \%$ and $42 \%$ patients were nulliparous, $29 \%$ and $28 \%$ were para $1,22 \%$ and $22 \%$ of patients were para 2 respectively for group A and group B. In our study mean gestational age of group A was $8.81 \pm 1.74$ weeks and group B was $8.61 \pm 1.78$ weeks. Mean haemoglobin for group A was $10.04 \pm 1.56 \mathrm{gm} / \mathrm{dl}$ and for group B was $9.8 \pm 1.22 \mathrm{mg} / \mathrm{dl}$. Mean RBS for group A was $119 \mathrm{mg} / \mathrm{dl}$ and for group B was $117.7 \mathrm{mg} / \mathrm{dl}$. All above demographic and laboratory parameters were insignificant.

We considered ultrasound parameters $\mathrm{SCH}, \mathrm{CRL}$ and FHR. Majority $85 \%$ in group A and $96 \%$ patients in group B had no subchorionic haematoma. $15 \%$ in group A and $4 \%$ in group B had subchorionic haematoma. The $\mathrm{p}$ value was 0.008 . The result was significant.

Mean CRL was $19.31(\mathrm{SD}=13.22) \mathrm{mm}$ for group A (aborted) and $22.17(\mathrm{SD}=15.49) \mathrm{mm}$ for group $\mathrm{A}$ (continued). Mean CRL was 16.44 ( $\mathrm{SD}=11.37) \mathrm{mm}$ for group $\mathrm{B}$ (aborted) and $23(\mathrm{SD}=15.1) \mathrm{mm}$ for group $\mathrm{B}$ (continued). The $\mathrm{p}$ value for $\mathrm{CRL}$ in group $\mathrm{A}$ is 0.16 and in group B is 0.0006 .

Mean FHR for group A (aborted) 108.89 (SD=14.46) per minute and for group A (continued) was 128.32 $(\mathrm{SD}=13.51)$ per minute. Mean FHR for group B (aborted) was $105.55(\mathrm{SD}=5.11)$ per minute and for group $\mathrm{B}$ (continued) was 127.12 ( $\mathrm{SD}=14.79)$ per minute. The $\mathrm{p}$ value for FHR in both group A and group B are $<0.0001$. The result is significant. The AUC for FHR and CRL is 0.846 (95\% CI $0.755-0.937$ ) and 0.606 (95\% CI 0.755 0.937), respectively. According to our study, CRL is $50 \%$ sensitive, $69.35 \%$ specific in predicting abortion with $50 \%$ positive predictive value and $69.35 \%$ negative predictive value. FHR is $76.32 \%$ sensitive, $90.32 \%$ specific in predicting abortion with $82.86 \%$ positive predictive value and $86.15 \%$ negative predictive value. These findings are consistent with study by Oun AEM et al and Maged. ${ }^{12,13}$ However, Maged and Al Mohamady et al (2016) reported that, there was no significant difference between groups as regard to crown rump length and these results are confirmed in the present work. ${ }^{13,14}$ Regarding FHR, results of the present study agreed with Doubilet and Benson's and Tannirandorn et al findings. ${ }^{15,16}$

According to our study mean CA-125 value for group A (aborted) $100.24(\mathrm{SD}=45.24) \mathrm{U} / \mathrm{ml}$ and for group $\mathrm{A}$ (continued) was 32.64 ( $\mathrm{SD}=41.6) \mathrm{U} / \mathrm{ml}$. Mean CA-125 value for group $\mathrm{B}$ (aborted) $32.45(\mathrm{SD}=15.94) \mathrm{U} / \mathrm{ml}$ and for group $\mathrm{B}$ (continued) was 16.39 (SD=9.5) U/ml. In both groups $\mathrm{p}$ value are $<0.0001$. The result was significant.

The AUC for CA-125 is 0.966 (95\% CI 0.922-1.011). According to our study, CA-125 is $84.21 \%$ sensitive, $96.77 \%$ specific in predicting abortion, with $94.12 \%$ positive predictive value and $90.91 \%$ negative predictive value. Previous studies concluding CA-125 as a good screening tool in patients with threatened miscarriage to predict pregnancy who aborted. ${ }^{17,18}$ While Fiegler et al (2003) used a cut-off value of $66.5 \mathrm{IU} / \mathrm{ml}$ with a sensitivity of $55 \%$ only and Schmidt et al (2001) used 65 $\mathrm{IU} / \mathrm{ml}$ as a cut-off value and reported a sensitivity of $50 \%$ for this level. ${ }^{19,20}$

\section{CONCLUSION}

Both maternal serum CA-125 measurement and USG are inexpensive, easily available, fast, non-invasive predictors of threatened abortion which may result in loss of pregnancy. But present study concluded that single raised maternal serum $\mathrm{CA}-125$ value has best predictive value than USG parameters (FHR, sub-chorionic hematoma, CRL) in women with threatened abortion.

Funding: No funding sources

Conflict of interest: None declared

Ethical approval: The study was approved by the Institutional Ethics Committee 


\section{REFERENCES}

1. National Institute of Health. Fact sheet: Pregnancy: Condition Information, 2015. Available at: https://www.nichd.nih.gov/health/topics/pregnancy/c onditioninfo. Accessed on 8 March 2021.

2. Rubio C, Simón C, Vidal F, Rodrigo L, Pehlivan T, Remohí J, et al. Chromosomal abnormalities and embryo development in recurrent miscarriage couples. Hum Reprod. 2003;18(1):182-8.

3. Redinger A, Nguyen H. Incomplete Abortions. Stat Pearls. 2021.

4. Saraswat L, Bhattacharya S, Maheshwari A. Maternal and perinatal outcome in women with threatened miscarriage in the first trimester: a systematic review. BJOG. 2010;117(3):245-57.

5. Arafa M, Abdel-Fattah M, Zeid HA. Outcomes of pregnancies complicated by early vaginal bleeding. East Mediterr Health J. 2000;6(2-3):457-64.

6. Yang J, Hartmann KE, Savitz DA, Herring AH, Dole $\mathrm{N}$, Olshan AF, et al. Vaginal bleeding during pregnancy and preterm birth. Am J Epidemiol. 2004;160(2):118-25.

7. Elson J, Salim R, Tailor A, Banerjee S, Zosmer N, Jurkovic D. Prediction of early pregnancy viability in the absence of an ultrasonically detectable embryo. Ultrasound Obstet Gynecol. 2003;21(1):57-61.

8. Nyberg DA, Mack LA, Harvey D, Wang K. Value of the yolk sac in evaluating early pregnancies. J Ultrasound Med. 1988;7(3):129-35.

9. Altay MM, Yaz H, Haberal A. The assessment of the gestational sac diameter, crown-rump length, progesterone and fetal heart rate measurements at the 10th gestational week to predict the spontaneous abortion risk. J Obstet Gynecol Res. 2009;35(2):28792

10. Tan S, Tangal NG, Kanat-Pektas M, Özcan AŞ, Keskin HL, Akgündüz G, et al. Abnormal sonographic appearances of the yolk sac: which can be associated with adverse perinatal outcome? Med Ultrason. 2014;16(1):15-20.

11. Felder M, Kapur A, Gonzalez-Bosquet J. MUC16 (CA125): tumor biomarker to cancer therapy, a work in progress. Mol Cancer. 2014;13:219-29.
12. Oun AEM, Ibrahem EM, Elaziz MRA. Role of both serum ca125 and ultrasound in prediction of pregnancy outcome in first trimester threatened miscarriage. Int J Life Sci. 2018;7(2):79-84.

13. Maged AM, Mostafa WA. Biochemical and ultrasonographic predictors of outcome in threatened abortion. Middle East Fertil Soc J. 2013;18(3):17781.

14. Mohamady MA, Fattah GA, Elkattan E, Byoumy R, Hamed DA. Correlation of serum CA-125 and progesterone levels with ultrasound markers in the prediction of pregnancy outcome in threatened miscarriage. Int J Fertil Steril. 2016;9(4):506-11.

15. Doubilet PM, Benson CB. Outcome of first-trimester pregnancies with slow embryonic heart rate at 6-7 weeks gestation and normal heart rate by 8 weeks at US. Radiology. 2011;236(2):643-6.

16. Tannirandorn $\mathrm{Y}$, Sangsawang S, Manotaya S, Uerpairojkit B , Samritpradit P, Charoenvidhya D. Fetal loss in threatened abortion after embryonic/fetal heart activity. Int J Gynaecol Obstet. 2003;81:263-6.

17. Eid M, Abdallah AK. Cancer antigen 125 (CA-125) and serum progesterone as predictors of fate of threatened abortion: case control study. Int J Fertil Steril 2017;7(4).

18. Sweed MS, Sammour HM, Bakr AA. Serum CA-125 for early prediction of miscarriage. Med J Obstet Gynecol. 2016;4(1):1077.

19. Fiegler P, Katz M, Kaminski K, Rudol G. Clinical value of a single serum CA-125 level in women with symptoms of imminent abortion during the first trimester of pregnancy. J Reprod Med. 2003;48(12):982-8.

20. Schmidt T, Rein DT, Foth D, Eibach HW. Prognostic value of repeated serum CA125 measurement in the first trimester of pregnancy. Eur J Obstet Gynaecol Reprod Biol. 2001;97:168-73.

Cite this article as: Yadav K, Ojha $\mathrm{P}$, Chopra A. Comparison of maternal serum CA-125 and ultrasonography findings as a prognostic marker in threatened abortion. Int J Reprod Contracept Obstet Gynecol 2021;10: 2253-8. 